\title{
Help chain: guidelines for design and operation in Lean Production Systems
}

\section{Diretrizes para projeto e operação de cadeias de ajuda em Sistemas de Produção Enxuta}

ISSN 0104-530X (Print) ISSN 1806-9649 (Online)

\author{
Alexandre Pelizzon ${ }^{1}$ (1) \\ Tarcisio Abreu Saurin ${ }^{1}$ \\ Giuliano Almeida Marodin²
} How to cite: Pelizzon, A., Saurin, T. A., \& Marodin, G. A. (2019). Help chain: guidelines for design and operation
in Lean Production Systems. Gestão \& Produção, 26(4), e1974. https://doi.org/10.1590/0104-530X1974-19

\begin{abstract}
Lean production aims at operational improvement by the elimination of waste and variability reduction. The lean practice known as help chain, which contributes to the lean goals is an underexplored topic. Thus, the objective of this paper is to propose guidelines regarding the help chain design and operation by addressing issues related to the definition of the events that need support from the chain and selection of the members to be involved. The proposed guidelines involve seven steps: (i) delimitation and evaluation of the scenario of application; (ii) identification and classification of abnormalities; (iii) identification of the types and contents of visual devices; (iv) identification of agents involved in the help chain; (v) definition of the operating logic of the help chain; (vi) training and qualification; and (vii) application and evaluation of the results. A partial application in the printing department of a tobacco's manufacturer plant is a basis for discussing the strengths and weaknesses of the guidelines.
\end{abstract}

Keywords: Lean production; Help chain; Routine management.

Resumo: O sucesso na implantação de muitas das práticas lean depende da existência de uma estabilidade produtiva básica. Por sua vez, um dos meios de se obter estabilidade é através de rotinas padronizadas para a solução das anormalidades, como as das cadeias de ajuda. O objetivo deste trabalho é propor diretrizes para o projeto e operação de cadeias de ajuda, tratando de questões como a definição de quais eventos necessitam do suporte da cadeia e a seleção dos membros que devem ser envolvidos. As diretrizes propostas envolvem sete passos: (i) delimitação e avaliação do local de aplicação; (ii) identificação e classificação das anormalidades; (iii) identificação dos tipos e conteúdos dos dispositivos visuais; (iv) identificação dos agentes envolvidos na cadeia de ajuda; (v) definição da lógica de operação da cadeia de ajuda; (vi) treinamento e capacitação; e (vii) aplicação e avaliação de resultados. Uma aplicação parcial em uma indústria gráfica ilustra o uso das diretrizes, servindo de base para a discussão de seus pontos fortes e fracos.

Palavras-chave: Cadeia de ajuda; Gestão da rotina; Produção enxuta.

\section{Introduction}

Brazilian companies have shown a keen interest in using lean production (LP) systems as a way to improve their operational performance (Saurin et al., 2010; Silva et al., 2011). LP aims to eliminate waste in production and reduce internal and external variability (Shah \& Ward, 2007). For example, standardized work aims to reduce the instabilities related to the operators working method, while the Kanban pull system seeks to reduce the variability that may be caused by the lack of materials.

However, these practices do not completely solve the variability problems, as instabilities occur daily and must be addressed in order to achieve high levels of operational performance (Smalley, 2005; Liker \& Meier, 2007; Campos et al., 2010). In this regard, the help chain is a lean practice that establishes a

\footnotetext{
${ }^{1}$ Programa de Pós-graduação em Engenharia de Produção e Transportes - PPGEP, Universidade Federal do Rio Grande do Sul UFRGS, Av. Osvaldo Aranha, 99, $5^{\circ}$ andar, CEP 90035-190, Porto Alegre, RS, Brasil, e-mail: pelizzon.alexandre@gmail.com; saurin@ufrgs.br

${ }^{2}$ Department of Management Science, Fisher College of Business, The Ohio State University, 600 Fisher Hall, 2100 Neil Avenue, 43210, Columbus, OH, United States of America, e-mail: gmarodin@moore.sc.edu
}

Received Jan. 7, 2015 - Accepted June 16, 2015

Financial support: None. 
standardized routine for identifying and resolving abnormalities in processes (Kamada, 2008).

The help chain is related to some of the 14 Toyota Production System (TPS) principles presented by Liker (2005), which include (a) creating a continuous process flow to bring problems to the surface; (b) stopping to fix problems to get quality right the first time; (c) using visual controls to expose problems; (d) analyzing the problem at source; and (e) making decisions by consensus and implementing them quickly. In addition, the use of help chains is implicit in one of the four rules that describe the tacit knowledge that underlies the TPS, namely that. "All customer-supplier connections must be direct, and there must be an unambiguous yes or no way to send requests and receive replies" (Spear \& Bowen, 1999, p. 98).

Despite the importance of the help chain, there is a dearth of studies on this topic. Moreover, the extant studies address the decisions associated with the help chain design and operation in a superficial manner, without presenting empirical validation (Andrade, 2001; Smalley, 2005; Flinchbaugh, 2007; Kamada, 2008; Oliveira, 2009; Campos et al., 2010; Wagner, 2011). Thus, the main objective of this paper is to propose and test guidelines for the design and operation of help chains. These guidelines were applied in a case study in the plant of a tobacco's manufacturer, in the printing department

\section{Help chain}

\subsection{Definition}

According to Flinchbaugh (2007), the help chain is a standardized way for the people who have identified abnormalities to ask for help, as well as for the appropriate staff to respond to that request. With support from the help chain, the affected employees actively deal with one issue at a time on the spot. Horst (2011) defines it as a network made up of operational and support areas with the objective of maintaining process availability, quality, and efficiency by implementing triggers and standardized measures to quickly correct abnormalities. Additionally, in a well-designed help chain, an employee knows exactly how to act when an abnormality is detected (Flinchbaugh, 2007).

In the present study, the help chain is defined as a practice that involves triggering alarms in abnormal situations to request help from individuals or teams who must act immediately in the required place in order to identify the existing problem, seek solutions, and manage the generated knowledge. However, as Spear $\&$ Bowen (1999) argue, lean-related practices, such as the help chain, are merely temporary countermeasures to cope with specific abnormalities and, therefore, will be useful only until either better approaches arise or the conditions involved undergo training or machine modifications as appropriated.

\subsection{Design and operation}

The initial steps involve detecting abnormalities to identify the main problems, define the types of help needed, separate problems by the area of responsibility, and define the related response time for each problem (Flinchbaugh, 2007; Horst, 2011). According to Andrade (2001), the chain operator should be the shift leader and the chain structure should contain at least one person from each production support area. Spear \& Bowen (1999) suggest that this structure should be sized according to the stipulated response time, the complexity of the abnormalities, and the skills and abilities of those involved.

After selecting the major problems, determining the response times, and scaling the help chain team, a quick-response plan (QRP) should be developed (Campos et al., 2010; Horst, 2011). This QRP should consist of standard procedures to be followed after the detection of a problem, along with specifying the basic corrective actions, triggering flow of the different levels of the help chain, the responsible work team, and deadlines for each level (Wagner, 2011). Furthermore, the response to the request for help should be standardized to avoid ambiguity as well as ensure what is to be expected from the agents at each level (Spear \& Bowen, 1999; Flinchbaugh, 2007).

Once the QRP has been developed, it becomes necessary to find a way to connect the employee who needs help with the employee who will provide it (Flinchbaugh, 2007; Horst, 2011), which is usually done through an andon. Andon is a Japanese term for "lamp" or "signal," and, in practice, it can take the form of a hand wave, sound, light, phone call or even, as per Jusko (2010), social media platform such as Twitter. However, regardless of the form, it should display the status of the process for the entire organization and signal the request for help to the person responsible for providing it (Ohno, 1997; Flinchbaugh, 2007; Kamada, 2008).

In the operation of the help chain structure, when a problem is detected, the employee must follow the corrective orientations defined in the QRP and try to solve the problem autonomously within the stipulated time interval. If this interval is not sufficient, the employee should trigger the first level of the help chain through an andon (Kamada, 2008; Oliveira, 2009; Campos et al., 2010; Horst, 2011). According to Spear \& Bowen (1999), this system often goes against the intuitions of managers, who usually encourage employees to solve problems on their own regardless of the time intervals involved and ask for help only when abnormalities reach large proportions. 
According to QRP, at the first level, a production team leader must support an operator within the expected time frame. If the problem persists, an andon should be used to trigger the responsible support personnel. If the problem is not solved, an andon should be used again to trigger the production supervisor (or manager), and so on in the defined hierarchy. All problems solved in the first level, whether solved or not and whether they stop the production or not, should be registered for further analysis in the second and/or third level(s) of the chain (Kamada, 2008; Campos et al., 2010).

The second level entails a brief daily meeting, coordinated by the leader and in the presence of the area supervisors, where the reasons for activating the chain and the actions taken should be discussed. Afterwards, the unresolved problems discussed in these meetings should be prioritized and the action plans to be implemented by the third level of the chain should be created by the area or even multi-departmental teams (Kamada, 2008; Campos et al., 2010; Horst, 2011; Maganhoto, 2012). Furthermore, as Liker \& Meier (2007) point out, if the measures that reach the root cause require a long-term study, it is necessary to act on some form of short-term recurrence containment.

\section{Research method}

\subsection{Research strategy}

This study employs the Design Science Research (DSR) methodology, which proposes an artifact to solve the problem. DSR's emphasis is on the development of solutions to problems and their evaluation rather than on the process of change generated by the introduction of the solution. Therefore, the novel artifact is applied as a form of validation, and it brings practical and theoretical knowledge (Dresch, 2013; Lacerda et al., 2013).

This study's adherence to DSR is noticeable as it develops a management artifact (i.e., guidelines for the design and operation of help chains), which aims at solving the problems through practical application in an organization as well as by prescribing guidelines useful to other contexts. Even though the company's analysts and coordinators helped in designing and validating the guidelines, the first author of this study was their main mentor.

\subsection{Case study scenario}

The selected scenario is the printing department of a tobacco manufacturer's plant. Subdivided into 15 departments, the plant employs 222 people working in three production shifts and one administrative shift. The printing department only supplies products to the companies it is a subsidiary of, as it is responsible for the production of approximately $98 \%$ of the final product packaging used by thos tobacco company based in Brazil. This corresponds to an average annual production of nearly 17,000 tonnes, or nearly 260 million square feet of packaging (over 350 different products), which is the only mode of communication and marketing still allowed for tobacco products in many markets.

In the printing department, the packaging and printing area receives and uses inputs from almost all other production departments. With the use of rotogravure technology, the printing department makes use of these inputs to produce finished or semi-finished products, depending on the product family.

Rotogravure printing is a direct graphic reproduction process in which art is reproduced on the substrate (usually paper) by direct contact with a perfectly uniform cylindrical surface (plated with copper, along with a low-relief art and chrome overlay) and washed with ink from one of the printing units of a rotary printer. This study selected the printing department based on the following criteria:

(i) It has great interdependence with other sectors;

(ii) It is the bottleneck of the whole production process at the plant;

(iii) It has low overall equipment efficiency (OEE);

(iv) It has physical barriers (e.g. large machinery) that make visualization difficult for other sectors; and

(v) It is installed relatively far from its support areas.

Criterion (i) is relevant because the inputs received from other sectors, or the resources from the sector itself, may be abnormal and require support, which the help chain can provide. Criterion (ii) is relevant because the bottleneck defines the final capacity of the production process and generates idleness in subsequent sectors, in which case the help chain can contribute to improving the capacity of the bottleneck. Criterion (iii) is relevant because the sector's OEE is affected by the slow delivery of support or complete lack thereof, which mainly affects equipment availability. Here, the help chain can make the support more agile and accurate. Criteria (iv) and (v) are relevant because distances and visual barriers make it more difficult to identify these abnormalities, in which case the help chain can provide visibility and a sense of urgency to the areas of responsibility.

Improvements in the bottleneck capacity and OEE indicator, mainly related to criteria (i), (ii) and (iii), were the main drivers of the researcher's decision to implement the help chain in the printing department, as these criteria will enable it to advance its strategy regarding the internalization of demands from other countries of South and Central America. 
The industry has four rotogravure printing machines, the general characteristics of which can be seen in Table 1. Each machine differs from the others in terms of its level of automation. Moreover, each has its own supervisory system, i.e., the operator enters the values of some parameters that will be used in the production, and the machines control and act on the maintenance of these parameters. Additionally, both the feeding of raw materials as well as the removal of products are performed manually on all the four machines.

As regards the organization of work, the sector employs 48 direct employees, with the teams fixed for each printer in each of the three work shifts. Moreover, the hierarchy and size of the teams vary according to the complexity of the operation of each machine (four employees on machine 1, three employees on each of machines 2 and 4, and six employees on machine 3). The production volumes and production sequencing are scheduled once a month and reviewed twice a week, and the production orders are created for each product according to scheduled weekly demands.

\subsection{Research steps}

\subsubsection{Overview}

This study was conducted in seven stages, which are as follows:

(i) Delimiting and evaluating the application site and aligning with the critical success factors (CSF);

(ii) Identifying and classifying the abnormalities;

(iii) Identifying the types and contents of the necessary visual devices;

(iv) Identifying the agents involved in the help chain; (v) Defining the help chain operation logic;

(vi) Training and capacity building; and

(vii)Applying and evaluating the results.

Table 2 presents the research steps, stakeholders, and documents used in this study.

\subsubsection{Application site assessment}

After delimiting the application site, an assessment of its adherence to the preconditions and critical success factors (CSF) for the implementation of the help chain was conducted using the diagnostic method proposed by Horst (2011), which was validated by Maganhoto (2012). Through the questionnaire, the quantification and diagnosis of the level of adherence of the scenario was enabled, allowing a plan to be drawn for the implementation of the help chain. Moreover, individual interviews were conducted with all the leaders of the printing sector, consisting of 6 coordinators and 5 managers, who assigned scores for each questionnaire item to generate a final score for the scenario.

\subsubsection{Identification and classification of abnormalities}

With the scenario delimited and evaluated, there was a need to define the abnormalities that would lead to the use of the help chain. Subsequently, there was a need to map the historical abnormalities, whether recurrent or not, as well as those likely to occur in the future, and classify them in the groups that would be directed to the areas of responsibility.

Two analyses were conducted to define the abnormality groups through Pareto graphs. One was used in relation to the number of abnormality events related to each group, while the other was used

Table 1. Overview of the Printing Sector Machines.

\begin{tabular}{|c|c|c|c|c|}
\hline Feature & Printer1 & Printer 2 & Printer 3 & Printer 4 \\
\hline Units & 10 units & 8 units & 9 units & 4 units \\
\hline Capacity & $400 \mathrm{~m} / \mathrm{min}$ & $400 \mathrm{~m} / \mathrm{min}$ & $250 \mathrm{~m} / \mathrm{min}$ & $500 \mathrm{~m} / \mathrm{min}$ \\
\hline Substrate & Up to $160 \mathrm{~g} / \mathrm{m}^{2}$ & $\mathrm{Up}$ to $160 \mathrm{~g} / \mathrm{m}^{2}$ & $\mathrm{Up}$ to $600 \mathrm{~g} / \mathrm{m}^{2}$ & $\mathrm{Up}$ to $600 \mathrm{~g} / \mathrm{m}^{2}$ \\
\hline Product & $\begin{array}{l}\text { Printed jumbo coil } \\
\text { (semi-finished) }\end{array}$ & $\begin{array}{l}\text { Printed jumbo coil } \\
\text { (semi-finished) }\end{array}$ & Case (finished) & $\begin{array}{l}\text { Printed jumbo coil } \\
\text { (semi-finished) }\end{array}$ \\
\hline $\begin{array}{l}\text { Automatic } \\
\text { controls }\end{array}$ & $\begin{array}{l}\text { Color register, visual } \\
\text { inspection, oven } \\
\text { temperature, substrate } \\
\text { tensioning, ink } \\
\text { viscosity, and substrate- } \\
\text { feeding device device }\end{array}$ & $\begin{array}{l}\text { Color register, } \\
\text { visual inspection, } \\
\text { oven temperature, } \\
\text { substrate tensioning, } \\
\text { ink viscosity, and } \\
\text { substrate- feeding } \\
\text { device }\end{array}$ & $\begin{array}{l}\text { Color register, visual } \\
\text { inspection, oven } \\
\text { temperature, substrate } \\
\text { tensioning, ink viscosity, } \\
\text { embossing, creasing, } \\
\text { cutting, substrate } \\
\text { accumulator, and } \\
\text { substrate-feeding device }\end{array}$ & $\begin{array}{l}\text { Color register, } \\
\text { oven temperature, } \\
\text { substrate } \\
\text { tensioning, and } \\
\text { substrate-feeding } \\
\text { device }\end{array}$ \\
\hline
\end{tabular}


Table 2. Steps, stakeholders and documents used.

\begin{tabular}{lll}
\hline \multicolumn{1}{c}{ Steps } & \multicolumn{1}{c}{ Involved } & \multicolumn{1}{c}{ Documents used } \\
\hline $\begin{array}{l}\text { (i) Scenario delimitation } \\
\text { and evaluation of the } \\
\text { scenario }\end{array}$ & $\begin{array}{l}\text { Plant managers (6 coordinators and 5 } \\
\text { managers) }\end{array}$ & $\begin{array}{l}\text { Assessment questionnaire of compliance } \\
\text { between scenario and CSF for } \\
\text { implementing the help chain structure }\end{array}$ \\
$\begin{array}{l}\text { (ii) Identification } \\
\text { and classification of } \\
\text { abnormalities. }\end{array}$ & $\begin{array}{l}\text { 2 process engineering coordinators and 2 } \\
\text { process analysts }\end{array}$ & $\begin{array}{l}\text { Abnormality registering system (via SAP } \\
\text { ERP) }\end{array}$ \\
$\begin{array}{ll}\text { (iii) Identification of the } \\
\text { visual device types and } \\
\text { contents }\end{array}$ & $\begin{array}{l}3 \text { production and maintenance managers } \\
\text { from the paper and cardboard department, } \\
2 \text { process engineering coordinators, 2 } \\
\text { process engineering analysts, 4 graphic } \\
\text { technicians (1 per machine), and 1 }\end{array}$ & $\begin{array}{l}\text { Printing company proprietary guidelines } \\
\text { its worldwide subsidiaries; production } \\
\text { note forms, quality defects, and } \\
\text { downtime; planned production calculation }\end{array}$ \\
& & $\begin{array}{l}\text { spreadsheet; quality assessment } \\
\text { worksheet; internal classification of }\end{array}$ \\
& & $\begin{array}{l}\text { occupational safety risk levels; and the } \\
\text { literature on the problem-solving process, } \\
\text { A3, andons, and visual management }\end{array}$
\end{tabular}

(iv) Identification of agents involved in the help chain

(v) Defining the help chain operation logic

(vi) Training the agents involved

(vii) Application and evaluation of results
3 production and maintenance managers from the paper and cardboard department, 2 process engineering coordinators, 1 maintenance coordinator, and 2 process analysts

3 production and maintenance managers from the paper and cardboard department, 2 process engineering coordinators, 1 maintenance coordinator, 2 process analysts, and 1 maintenance analyst

3 production and maintenance managers from the paper and cardboard department, 10 process analysts, and operators from all the printing production sectors

3 production and maintenance managers from the paper and cardboard department, 10 process analysts, and operators from all the printing production sectors.
Hierarchical structures of the printing and maintenance areas; placement of employees in work shifts; matrices of functional competences and professional history (length of the experience in the function)

Documents and products from previous steps; historical records of break and fail reports (BFR); mapping of potential abnormalities; previous time and movement studies of the Maintenance department; and the literature on routine management

All the documents/products resulting from the previous steps and literature on help chain, A3 process, routine management, and visual management

Structures and routines created for the help chain, resulting from the previous steps; production system (OEE and scrap) metrics pre- and post-implementation; and unstructured interviews. in relation to the total downtime caused by these problems. Based on this, a prioritization index was generated by crossing the information from both analyses, which allowed the prioritization of the groups with the highest impact.

Because the abnormality recording system is via SAP ERP (integrated enterprise management system provided by the company SAPAG), the information about the abnormalities (e.g. downtime, reasons, impacts) had already been recorded by the company. Therefore, we analyzed the period between January 2013, when the groups and the records format pattern were updated, to August 2014. This period comprised 16,970 records that referred to the four printing presses.

\subsubsection{Identification of the types and contents of the necessary visual devices}

Developing standardized charts for the employees to visually manage the most relevant production-related information was necessary for managing the first level (or operational) help chain routine. These charts should be arranged close to the machines and present the data such as the responsible team, product, planned production, actual production, machine speed, scrap, quality impacts, abnormalities encountered, and help chain trigger records, among others. Moreover, the charts should be designed to accommodate the completion of each of the three work shifts in order 
to allow the simultaneous analysis of the current and the last two shifts.

To manage the help chain at the second (or managerial) level, it was also necessary to develop standardized charts, which ensured the uniformity and centralization of information collected by the second-level agents. Second-level charts should present the information in groups according to the content to which they refer, not according to the machines. This is because this approach facilitates the discussion and critical analysis of the topics between the managers, regardless of whichever machine they manage.

Thus, there should be charts related to, for example, production and abnormalities. Moreover, the availability of a place dedicated to the help chain was indicated so as to concentrate the information related to its control and management, besides allowing the periodic follow-up meetings at the second level and/or critical analysis meetings at the third and fourth levels.

It was also necessary to define a tool for root cause analysis and its subsequent treatment by using the A3 problem-solving process (Sobek \& Smalley, 2011). Finally, at this stage, one of the most important material resources in the help chain was defined, which was directly dependent on the characteristics of the scenario and the discipline of those involved: the andon.

\subsubsection{Identification of agents involved in the help chain}

The agents involved in the help chain were defined simultaneously with the help chain operating logic (section 3.3.5). Afterwards, these definitions were integrated and involved the analysis of the hierarchical structures of the print area and the area of responsibility selected from the guidelines of subsection 3.3.2, the placement of the employees in these two areas to work shifts, and the matrices of functional competences. At the request of the printing management, other factors such as the time of experience in the function were also taken into consideration.

It was then possible to structure which employees of the operational areas would be involved at each level of the chain and what their responsibilities would be. The second-level employees - whose role was to be involved in routine activities, carry out follow-ups during the shifts, sponsor the chain, and periodically validate the results obtained - were also identified at this stage. The third and fourth levels would have their employees selected at the time they would be triggered according to the particularity of each abnormality to be treated, and this selection would be made by the consensus of the employees at the second level of the chain.

\subsubsection{Defining the help chain's logic of operation}

The next step in implementation was to define the structure and logic of help chain operation, which was done simultaneously and in integration with the identification of the actors involved in the help chain (section 3.3.4). The chain was segmented into four distinct levels, but with supplementary and at times sequential actions.

The first level was structured with a focus on the operational scope by acting on the abnormalities as a way to restore the stability and involving employees of the operation and the selected responsibility area selected. Based on the history of detected abnormalities and the possible risks mapped, a series of QRPs were then created referring to the selected area of responsibility. Moreover, a working routine was structured at the first level that involved production leaders (production analysts) who were supposed to support the production and supply chain throughout their shift. This level should also include operational control charts created during the development of the guidelines for material resources.

The second level is focused on chain management as a way to restore and maintain stability as well as discuss improvements with the coordinators, managers, and area representatives. For this, it was necessary to structure a routine of data collection rounds, follow-up meetings, and results. This level should also generate action plans to contain or remedy any unresolved or contained abnormalities or, if further study is needed, trigger the third level of the chain.

The third level was structured with a focus on more complex and specific demands related to the treatment of abnormalities that have not yet had countermeasures in place or when they are ineffective. This level should be formed by multifunctional teams composed of collaborators specialized in their area of expertise.

The fourth level was structured focusing on the treatment of abnormalities that have been identified as common causes or that are highly complex, requiring the conduction of a project structure for their study and solution. This would be related to a method, such as the six-sigma approach, and would require specifically dedicated contributors.

\subsubsection{Training and qualification}

After the previous steps were followed, training activities were structured around the operation and management of the visual devices created, the use of elaborate analysis tools, the structure, routines, and logic of operation of the chain, the flow of information and the direction of discussions, and the management of the generated knowledge. These issues should be addressed through different forms of training, 
including training employees at all levels, and greater focus should be put on management and sponsorship (at the second level) or the operationalization of the chain (at other levels).

Not only the employees of the selected machine and area of responsibility, but also those considered references from other sectors were trained in order to best utilize the investment made and implement this training on other sectors/areas in the future. It is important to note that this guideline was worked in parallel with the previous guidelines, allowing those involved to acquire knowledge and gradually adapt to the new work format.

\subsubsection{Application and evaluation of results}

After the pilot application and monitoring process, the results obtained were measured by comparing the existing metrics before (January-August 2014) and after (September-November 2014) the implementation of the help chain. This included the OEE as well as the opinion of some of the stakeholders (managers, area representatives, and machine managers) obtained through unstructured interviews on the impacts of the help chain's implementation.

\section{Results}

\subsection{Application site evaluation}

According to the results of the questionnaires, the highest average score (4.42) was obtained by the OEE attribute, and the lowest average score (3.00) was obtained by the machine stability attribute. On a scale from zero to five, the final average score of the evaluated scenario was 3.7 with a standard deviation of 0.29 . Although the final average score obtained is equal to the cut-off point defined by Horst (2011), it indicates that it would be able to receive the implementation of the help chain.

\subsection{Identification and classification of abnormalities}

The reasons for using the help chain were mapped. An abnormality was defined as an event that could affect the productivity and/or quality of the operations to the point of causing production downtime or delays. While safety issues are also considered abnormalities, they are handled with special attention and treated as the top priority by the company, not being part of the help chain.

The impact of the abnormality records in relation to the number of abnormality events related to each group were analyzed through the Pareto graph, as presented in Figure 1.

Impacts in relation to the total downtime caused by abnormalities related to each group were also analyzed through the Pareto graph, as presented in Figure 2.

Both total downtime and number of stop events are relevant and negatively affect the process. The former mainly affects availability and the latter mainly affects quality, because rotogravure technology rotationally prints overlapping color patterns and, with each small stop, that impression needs to be re-synchronized, generating scrap.

Groups were classified according to a prioritization index generated from information about the position they occupied in each of the two analyses. In each analysis, each of the 14 groups received a unique integer score from 1 (least impactful) to 14 (most impactful). Subsequently, the values assigned to the same group were multiplied, generating a final prioritization value, as can be observed in Table 3. It should be noted that although it appearing in the stratifications, the group called Managerial is related to registered stops for which it is not possible the application of a help chain (stops for training, meetings, announcements, among others), and the times related to this group are scheduled and discounted from the OEE.

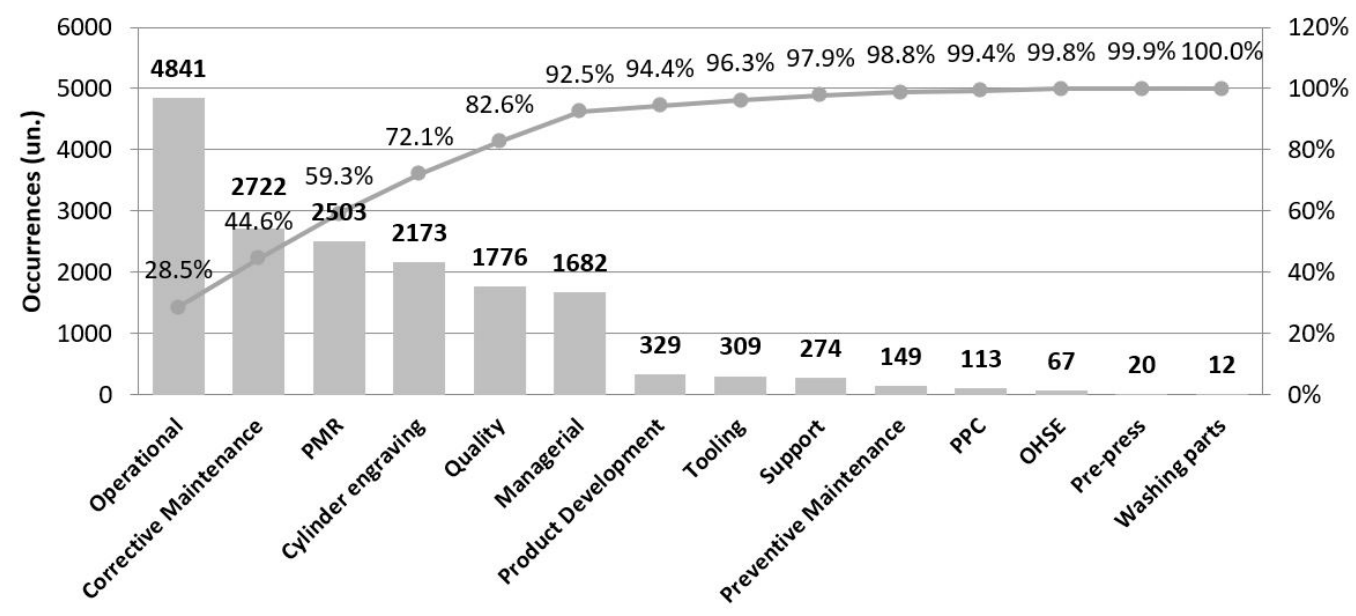

Figure 1. Pareto graph of number of occurrences per group (area of responsibility). 


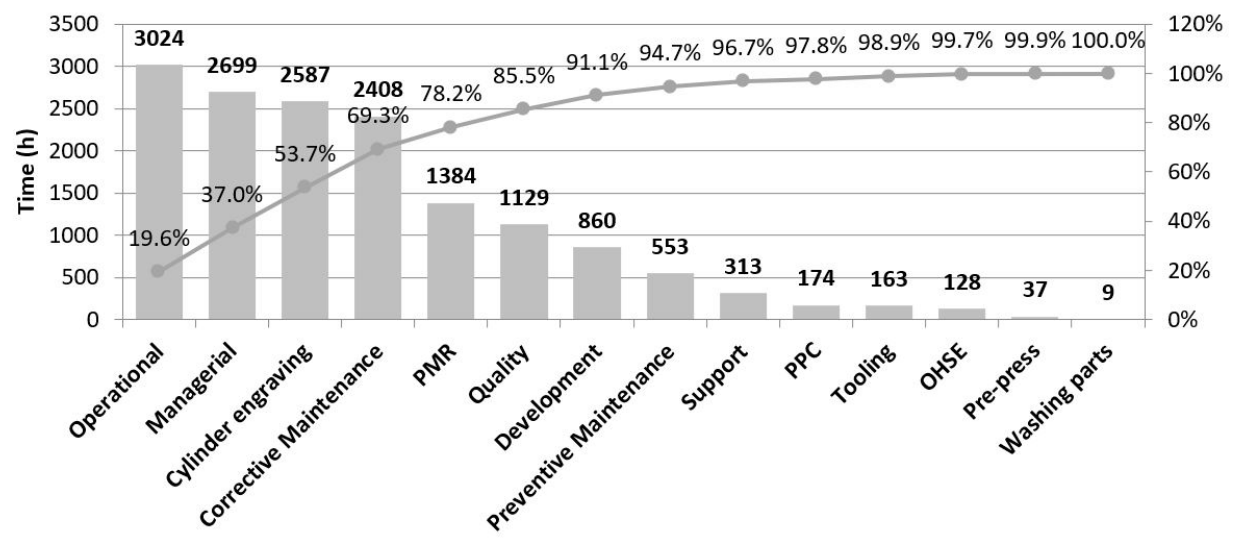

Figure 2. Pareto graph of total downtime by group (area of responsibility).

Table 3. Prioritization of groups (areas of responsibility).

\begin{tabular}{lccc}
\hline \multicolumn{1}{c}{ Group (area/sector) } & $\begin{array}{c}\text { Score } \\
\text { Number of events }\end{array}$ & Overall downtime score & Priority indicator \\
\hline Operational & 14 & 14 & 196 \\
Corrective Maintenance & 13 & 11 & 143 \\
Cylinder engraving & 11 & 12 & 132 \\
PMR & 12 & 10 & 120 \\
Managerial & 9 & 13 & 117 \\
Quality & 10 & 9 & 90 \\
Development & 8 & 8 & 64 \\
Support & 6 & 6 & 36 \\
Preventive Maintenance & 5 & 7 & 35 \\
Tooling & 7 & 4 & 28 \\
PPC & 4 & 5 & 20 \\
OHSE & 3 & 3 & 9 \\
Pre-press & 2 & 2 & 4 \\
Washing parts & 1 & 1 & 1 \\
\hline
\end{tabular}

PMR = Pre Make Ready; PPC = Production Planning and Control; OHSE = Organizational Health, Safety \& Environment.

The operational group was prioritized to have a help chain structure. However, as its name implies, the abnormalities contained in this group (such as tearing or breaking of paper in process) are dealt with by employees in the area of operation itself, i.e., there is no need to implement a help chain specific to the abnormalities of the operational group. In this case, the first group selected for the practical application of the guidelines proposed in this study was the corrective maintenance group, whose responsibility for the support and treatment of abnormalities involves the maintenance sector.

\subsection{Identification of the types and contents of the necessary visual devices}

The company that owns the printing operations had already taken steps to implement the lean philosophy in its worldwide strategy through meetings involving employees from operational to managerial levels. Material resources to manage production, such as charts, physical spaces, control tools and documents - adaptable to the context of each company operation - had been created. The control room was adapted to suit the graphic needs with charts to monitor occupational safety, production, abnormalities. Quality and control charts were displayed by the main machines of all productive sectors of the printing press, as well as abnormality treatment processes and andons.

Standardized production control charts were developed to manage the help chain routine at its first level, one for each of the four machines in the sector. These charts have placeholders for each of the three shifts, allowing the machine staff to record information relevant to their work shift and ensuring that at the beginning of a shift it is possible to view information for the last twenty-four hours simultaneously (Figure 3 ). 
The upper part of the chart is common to the three shifts: there is a space reserved for filling in the date, planned production, performed production. Just below are the axes for building the planned and achieved production graph (in tonnes) as a function of time (in minutes), to be updated every 20 minutes. It should be noted that the company does not use the concept of takt time (i.e., customer demand rate), but it can be calculated since it can vary from day to day without major impacts with no need to rebalance production. Further below, each shift has its own space, with fields for registering information about: team; waste generation; printed products; quality notes; main stops and times; action plans; and points of attention related to occupational health and safety. At the bottom of the chart, common to the three shifts, are also three acrylic displays: the first for the list of pending action plans; the second for the help chain trigger log list; and the third for the availability of QRPs related to the action of the aid chain.

A control room (Figure 4) was specially designed to manage the routine of the help chain's second level

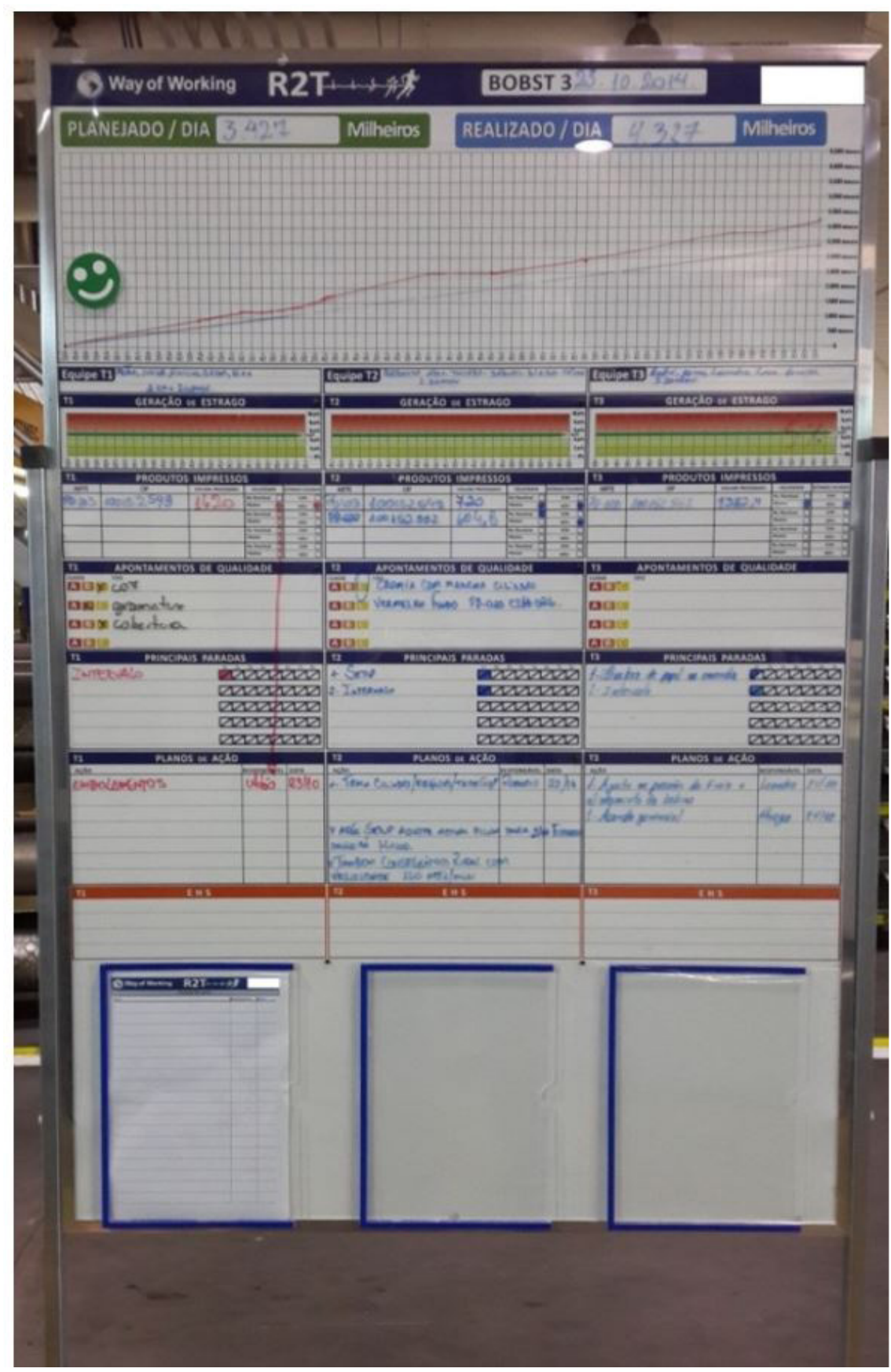

Figure 3. Production control chart filled out by a machine team. 
including a computer, video projector and meeting table. The standardized management control charts were created and properly allocated in this room.

The chart created for safety-related management control (Figure 5) has fields for filling in information about number of reports of potential nonconformities, near misses and accidents on each machine in relation for each day of the week; risk level identified on each machine; and action plans specifically related to occupational safety and health, with responsible people and deadlines.

The chart for production-related management control (Figure 6) has fields for registering planned versus actual production information for each machine on each day of the week; the quantity of quality deviations found on each day of the week, with their related degrees of criticality; the planned and actual scrap values; and the monthly-accumulated OEE values of each machine.

Beside this chart is one for abnormality-related management control (Figure 7), with fields for filling in information about the main daily impacts

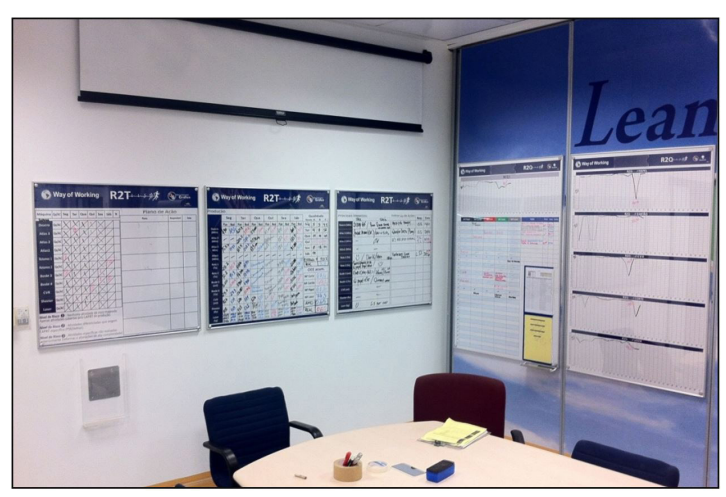

Figure 4. Help chain's control room.

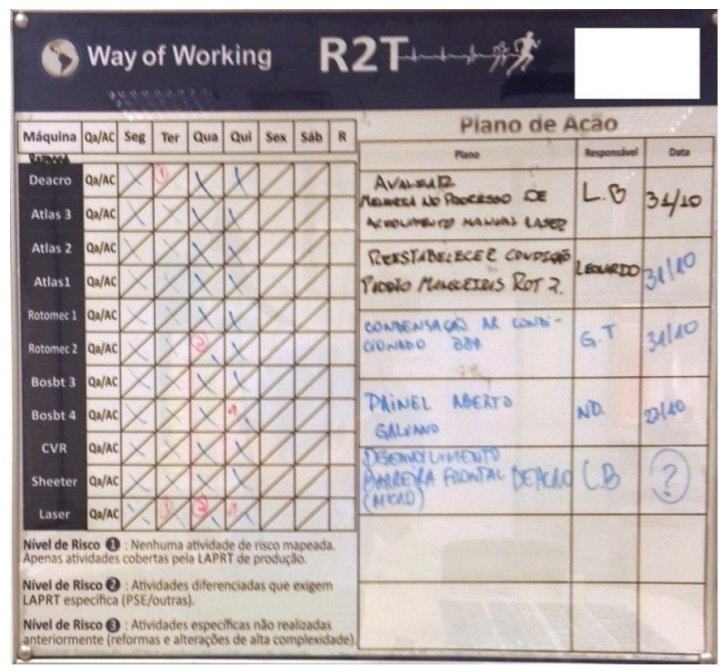

Figure 5. Management control chart related to occupational safety and health. found on each machine and the corrective measures taken by operators or during the daily meeting, with responsible people and deadlines.

There are two other charts to display information related specifically to the control of quality events (Figure 8). These charts provide the following information: the main quality deviation found per day on each machine; the daily product review scores provided by internal and external customers; and action plans with a focus on improving end-product quality.

The information displayed in the charts allows a weekly and / or monthly control visualization of production and help chain related events and indicators, and is updated daily. Monitoring of this and other relevant information takes place during the follow-up meeting in the control room, daily at $9 \mathrm{am}$, involving the second level of the chain and the area representatives (as needed).

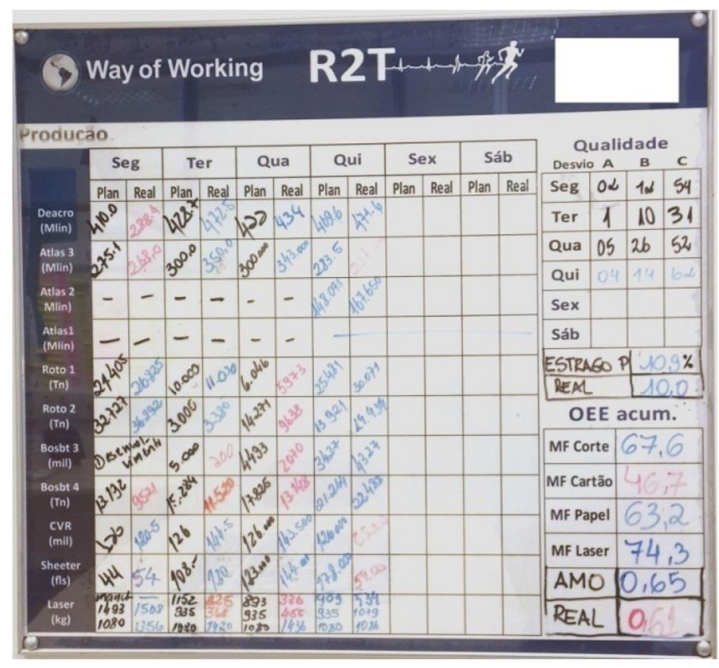

Figure 6. Production-related management control chart.

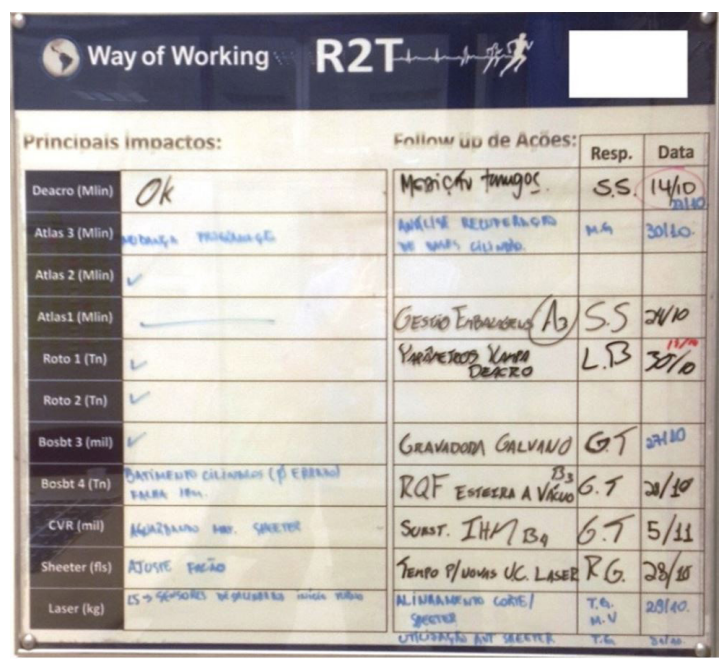

Figure 7. Abnormality-related management control chart. 
With the help of an external consultant, a standard A3 problem-solving document was created to address abnormalities whose root causes are harder to find so as to implement corrective actions. Highly complex abnormalities requiring further studies (usually with a stronger statistical base) are tacitly defined and directed to be dealt with in six sigma projects, in a sector that previously existed in the printing company. In fact, as stated by Bendell (2006) and Snee (2010), six sigma way is connected with Lean Production insofar as it provides the appropriate approach for the resolution of more complex and specific abnormalities whose solution is still unknown.

Finally, different types of andons were analyzed, two of which were selected. Identification of the abnormal situation would occur through an existing andon system on the machines, with flashing yellow signals to identify decreased target production speeds and flashing red signals in conjunction with audible signals to identify machine downtime due to the abnormality. Due to the great distance and physical obstacles between sectors / areas, the high level of environmental noise and the high costs involved, it was defined that two-way radios would be used as andons to activate the help chain, since all the employees involved in the chain already had such a device.

\subsection{Identification of agents involved in the help chain}

As already mentioned in section 3.2, the printing area has 48 employees divided into four machines and three shifts. The team hierarchy on each machine in the sector is related to the technological resources of each machine (cited in section 3.2) and is structured as shown in Figure 9, being the same for the three shifts.

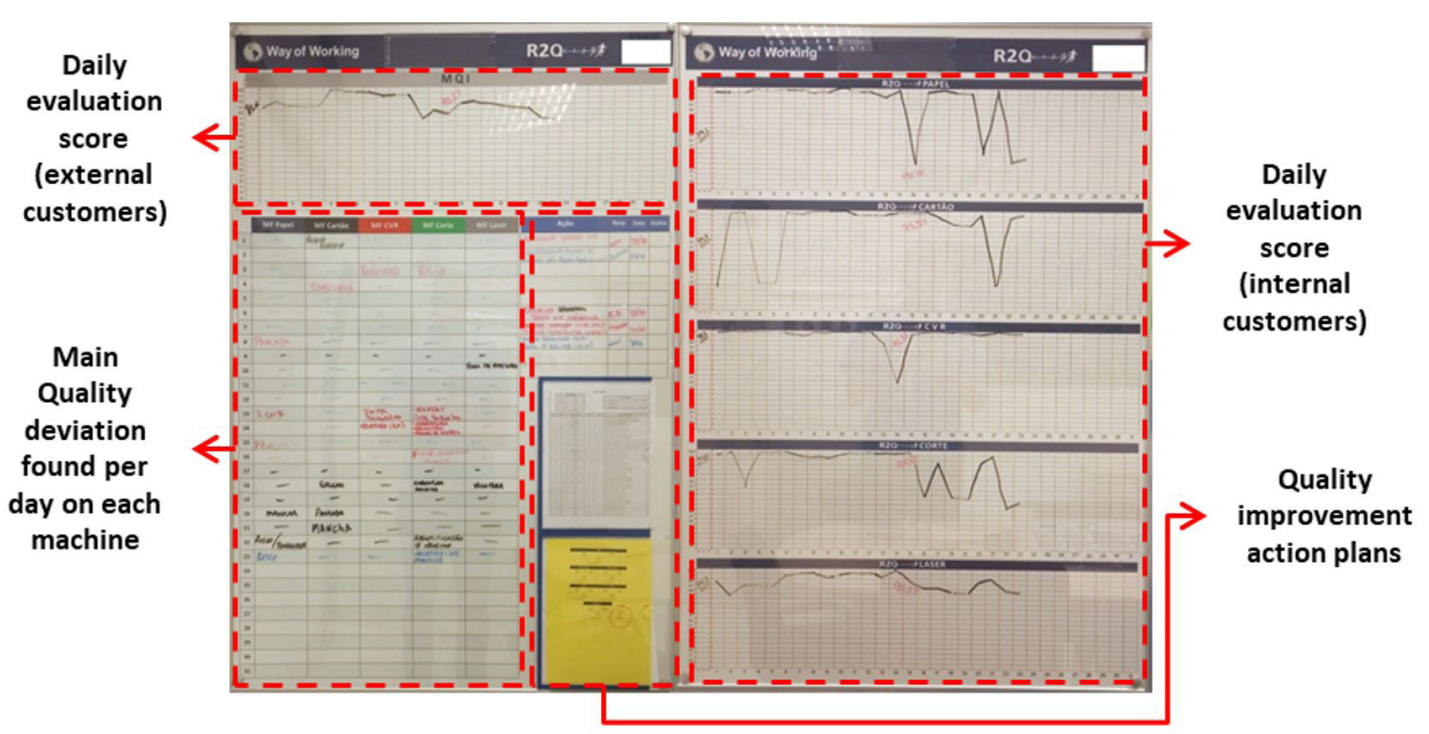

Figure 8. Quality-related management control chart.

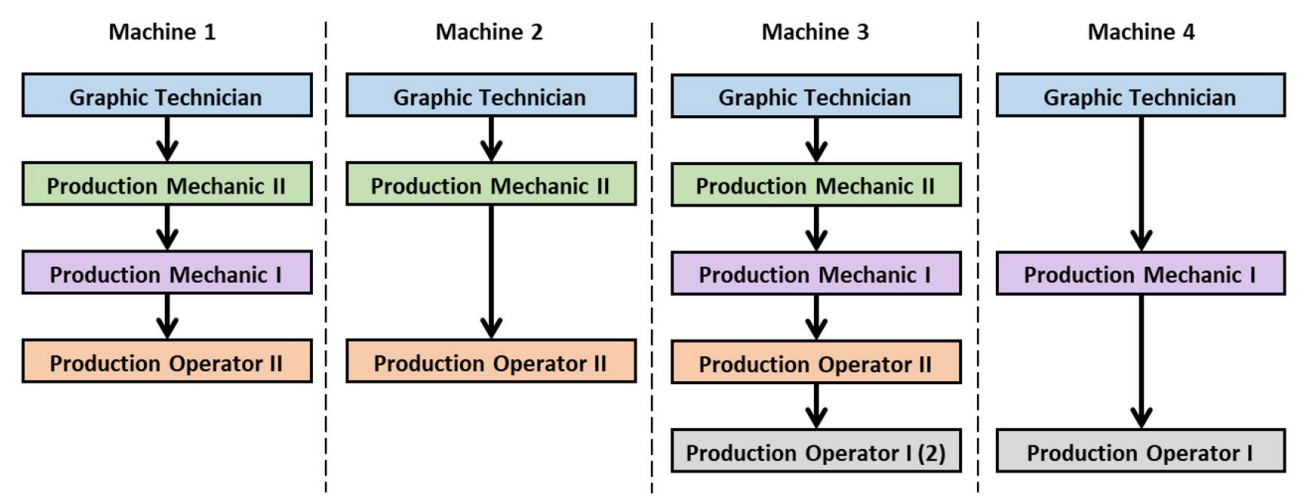

Figure 9. Hierarchy of printing area's teams (per machine). 
The position of graphic technician is the highest hierarchical level in the teams, as this employee is responsible for all issues related to production on his machine in his respective shift. Although the positions of Production Mechanic have a lower hierarchy, the employees who occupy these positions usually have the best technical knowledge about the equipment, among the other team members. For these reasons, it was defined that Production Mechanics and Graphic Technicians would have different help chain routines during their work shifts, which will be detailed in section 4.5.

To define the agents related to the Maintenance area, mapped as a priority support area and which received the first help chain of the printing company, the following were analyzed: (i) the hierarchical structure of the area (Annex A); (ii) the distribution of employees in relation to shifts and company time (Annex B); and (iii) the functional competence matrix (Annex C). These data allowed us to identify the availability of employees in each shift and their degree of competence in order to provide the necessary support when the printing area activated the help chain.

Each shift should have at least one employee at each hierarchical level to act as the chain agent. At hierarchical levels where there was more than one employee in the same shift, the employee with the highest functional capacity to act as a chain agent was selected based on the performance matrix. Although the specialists and the coordinator are allocated in the intermediate shift (business hours), they may be called at any time due to the responsibility associated with their positions. These analyses enabled defining that the following maintenance sector agents would be involved: maintenance mechanics; mechanical maintenance technicians; electronic maintenance technicians, maintenance analysts; maintenance specialists, maintenance coordinator; and production and maintenance manager, as well as the senior manager of printing operations.

The following were also included with routines defined in the chain structure: three production analysts (each in a shift), as they monitor production on the shop floor and assist teams in controlling and managing their activities, as well as all the managers and coordinators. Their roles and functions in the chain structure management and routine will be detailed in section 4.5 .

\subsection{Defining the help chain's operational logic}

To specify the operational logic of the first level of the chain it was necessary to create the QRPs simultaneously and identify the agents involved in the help chain, as already mentioned. To build this logic of operation, it was defined that when detecting an abnormality and its effect, the graphic technician should immediately trigger the production analyst, who should start the execution of the related QRP, together with the production mechanic. The production mechanic was defined as responsible for carrying out the checks and actions described in the QRP, regarding his function; the production analyst as responsible for monitoring these checks and actions; and the graphic technician as responsible for following up, manually monitoring the time and triggering the next agent in the chain through the mobile extension, whenever an abnormality persists and its cause is not found by the responsible agent within the stipulated time limit. The next triggered agent is responsible for performing the checks and actions mapped to his role in the QRP, within the time limit. And so on for the other mapped agents in the chain.

The abnormalities presented by the printing machines were analyzed to create the QRP, using the historical records of break and failure reports (BFRs), which were already being used by the Maintenance team. QRPs are documents completed after an incident is answered and contain a summary of the detected effects, checks and actions taken, and the solution found. The maintenance team also helped map the potential abnormalities, i.e., those that, although not historical, may occur. From the listing of these two types of abnormalities, the QRPs for the corrective maintenance help chain were then created.

Although a QRP was developed for each abnormality, it was defined that all QRPs should involve the same forms of activation. However, the agents involved and the checks and actions to be performed by each of them are different among the QRPs, insofar as they are defined according to each specific abnormality. The stipulated timeouts for each agent are also different in the QRPs, as they relate to the workload of the checks provided in each QRP. Times can range from small intervals for treatment of easily contained / resolved abnormalities to larger intervals for more complex abnormalities, and these are known through a motion and time study that was conducted by the maintenance team in an earlier period to the present work.

At this first level, the graphic technician is also responsible for completing the standardized production control chart containing all relevant shift information, whether related to production or to abnormalities identified and addressed by the help chain. Also at this level, when no abnormalities are occurring, the production analyst is responsible for monitoring the production, acting as leader and facilitator, in order to assist the teams in their demands.

The second level can be defined by help chain management and control, characterized by well-defined routines that support the entire developed structure. 


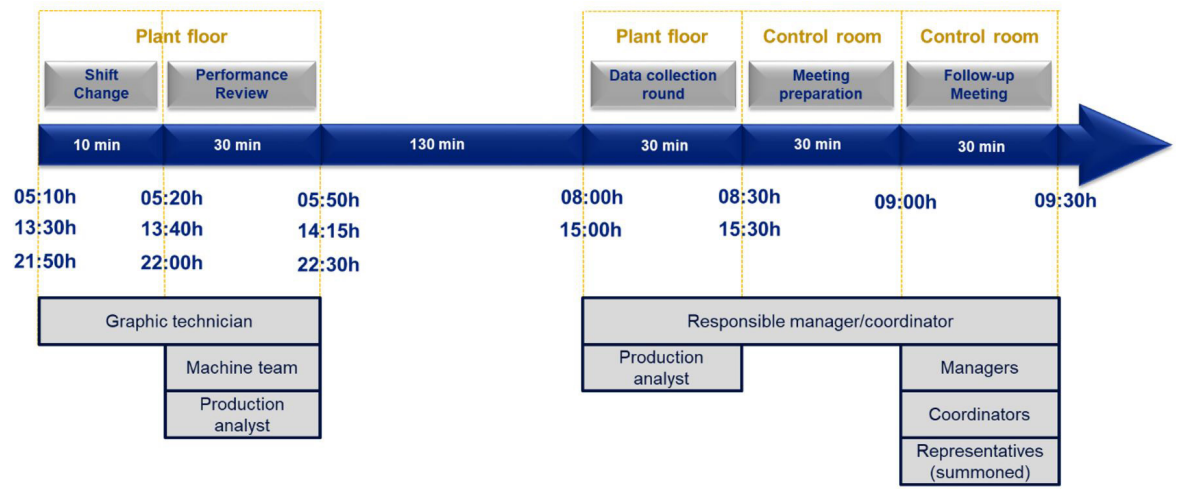

Figure 10. Representational scheme of the help chain's daily routines.

These can be seen in Figure 10 and will be detailed next.

During the shift change, the graphic technician must provide details of the production control information of his own and the previous shift to the next shift's graphic technician, through the information in the standardized production control chart. This ensures that the teams of the three shifts have visibility of the last 24 hours of operation of their machine and are aligned with all information.

Immediately after the shift change, the machine team conducts a performance review with the production analyst, based on the information on the chart, in order to identify the main difficulties that occurred in the last three shifts, to check the progress of the pending actions under the team's responsibility and prepare the information for discussion with the manager or coordinator in the data collection round (in the case of the first shift team). In the second and third shifts, and shortly after the performance review, the information from the earliest shift is erased and the current shift information begins to be filled.

Managers and coordinators take weekly turns in the data collection round, each being responsible for the routine during their period. In this round, accompanied by the production analyst, the manager or coordinator must collect information from the production control chart, which will feed the control room management control chart.; He should be informed about the impacts and actions conducted in the last three shifts (24 hours), and he must report the key points signaled in the performance review conducted by the team.

In preparing for the follow-up meeting, the manager or coordinator who conducted the data collection round should update the management control board; update status of action plans; critically evaluate the collected data; and prepare the agenda for the follow-up meeting, based on deviations from the goals. If necessary, the support area representatives who will be involved in mapped actions during the next routines should be present.

The follow-up meeting involves all managers and coordinators, as well as the area representatives convened. The manager or coordinator responsible for preparing the meeting should present the updated management control chart and start discussing the agenda. Participants should then: critically evaluate the effectiveness of action plans already applied to correct deviations in the agenda; discuss the need to create new plans; follow up on all pending plans under their responsibilities; and follow up on medium- and long-term projects and actions, as well as adjust the deadlines, if necessary. Afterwards, participants must lead their teams according to the alignment and objectives validated at the meeting.

Biweekly supervision meetings also take place, with the attendance of the same participants of the follow-up meetings and the presence of the senior print manager. This meeting is held along the same lines as the follow-up meeting, but discussions are centered around the last two weeks of production, mainly addressing the most impactful deviations, the updating the action plan and the results achieved by the chain. Finally, the proposed goals for the new biweekly cycle are also evaluated and, if necessary, new strategies to achieve them are aligned.

Strong knowledge allied with team multi-functionality describes the third chain level. Employees from the focus areas and representatives from other areas led by managers and / or coordinators work with the matters usually arising in follow-up meetings, related to both abnormalities that escalated to the last agent in the chain, i.e., were not resolved within the stipulated time, and reoccurring issues. This level utilizes the A3 process for problem solving as it allows analysis that are more robust and better structured action plans. This level, however, can also be triggered by the second one to perform process A3 analysis of any abnormality mapped by this level. 
At the fourth level, six-sigma trained collaborators are summoned to conduct studies of abnormalities. A specific area focuses on applying this project structure in the printing press, which, besides actively capturing demands, is available to receive demands from the help chain that fit this scope. Projects of this level, however, are conducted in the medium and long term and are characterized by their greater complexity, which is tacitly defined, as already discussed in section 4.3.

\subsection{Training and qualification}

All the printing machine teams received theoretical and practical training on:

(i) The instructions for completing production control charts;

(ii) The recommendations on shift change procedure;

(iii) The flowchart of the routine analysis performed by the management and key internal actors in the control room;

(iv) The use of problem analysis tools (Ishikawa diagram and five whys) and process A3;

(v) The identification and registration of the operating abnormalities; and

(vi) The use of QRPs and the help chain trigger flow.

The individuals on the second level also received training on the help chain structure. Some other points also deserved more specific alignment meetings and training sessions for this level, such as (a) the form of social interaction with the employees working with the machines to capture the consolidated information for the last three work shifts gathered during daily rounds; (b) the manner of conduction and sequencing of topics that should be addressed for control room analysis; and (c) the way to conduct the $\mathrm{A} 3$ process and fill out the standard $\mathrm{A} 3$ document.

\subsection{Application and evaluation of results}

The structure built for the help chain was partially implemented in the printing department between August and September 2014. Led by the printing press' senior management all the programmed structures and routines were implemented and put into operation, except for the execution of the QRP and the triggering of the agents (at the first level). This option was adopted because of the political moment in which the printing company is involved. This has resulted in a negotiation process that may culminate with the sale of its operations to another multinational company whose key processes are fully oriented to the printing market. In this case, due to the instability in relation to the investments and the readjustment of the number of operational employees, the full implementation of the structure was postponed.

In September, with the structure partially implemented in the print area, there were improvements in the main indicators of the sector, especially the OEE (with increases between $3.07 \%$ and $10.44 \%$, depending on the machine) and the scrap (with reduction from $8.65 \%$ to $8.10 \%$ ). However, in October and November, these results registered a slight worsening. The sector was mainly impacted by historically unusual abnormalities such as the delay in the delivery of raw materials by some external suppliers and the imminence of an outcome for the sale negotiation of the printing area, which generated apprehension and fear among the collaborators. However, both the good initial results and the worsening of the subsequent two months do not necessarily indicate a causal relationship with implementation. Therefore, the development of the process has to be monitored for a longer period with the structure in operation so that it is possible to confirm the evolution of its results quantitatively.

According to the interviews conducted with some employees, the implemented structure was unanimously approved and several benefits were pointed out. These improvements included (a) the employees at the operational level were better appreciated for being able to give greater visibility to their routines and demonstrate their analysis skills through the implemented structure; (b) the abnormalities were evidenced and their analyses became deeper and more scientific, thereby reducing their recurrence; (c) the machine production control was made easier; and (d) the quality and reliability of the information increased.

The use of the standardized production control chart also showed the anticipation in the production (see Figure 3 in section 4.3) as in many instances, the scheduled production was met in less time than available, and the next production orders were anticipated. This anticipation goes against what the lean model preaches (i.e., producing at the right time, quantity and time frame). From this evidence, an indicator was created that evaluated the adherence of production to the schedule, thereby preventing production anticipation to the point of affecting other areas (such as the generation of unnecessary inventories).

In addition, the daily presence of managers and/or coordinators on the shop floor was positively highlighted by everyone as a determining factor in making the abnormality resolution process more agile, proactive, and standardized. Moreover, during the structuring and alignment meetings of the help chain with the 
managerial level, there was a consensus that this level should change its focus, starting to monitor and act on middle indicators (for example, grades assigned to teams through internal audits about the correct use of machine parameters and resources) rather than just reactively evaluating and acting on end indicators (e.g., percentage of machine-generated scrap). This shift in focus aroused the need for technical training on the process at the managerial level, which allowed managers and coordinators, rather than being people managers, to become really process managers.

\section{Conclusions}

\subsection{Theoretical contributions}

The main theoretical contribution of this study was the creation of guidelines for help chain design and operation, which were evaluated practically through their application in a packaging print area assisted by a partially implemented help chain structure. The proposed guidelines involve:

(i) Delimiting and evaluating the application site and adherence to FCSFs;

(ii) Identifying and classifying the abnormalities;

(iii) Identifying the types and contents of the necessary visual tools and devices;

(iv) Identifying the agents involved in the help chain;

(v) Defining the help chain operation logic;

(vi) Training and capacity building; and

(vii)Applying and evaluating the results.

These guidelines can be useful for companies in any industry or service sector. This contribution consists of a normative theory for the implementation of lean system practices and principles. Such a theory reflects the development of guidelines on which actions will or will not achieve the desired result (Carlile \& Christensen, 2004).

By applying the guidelines and partially implementing the structure, it was possible to validate their applicability, as well as obtain results and benefits for the printing area. Moreover, some difficulties and gaps found in the literature, which were either not addressed or only superficially approached in the previous works, have been covered by the present work. These involved:

(i) The definition of the events that need chain support, which was explained through impact classification, Pareto charts, and area prioritization;

(ii) The definition of the moment when the support should arrive, which was explained both by using QRPs to define the checks and actions and studying time and movements to determine the performance time limits;

(iii) The definition of the sectors and teams to be involved, which was explained by routine definition and information flows, as well as the responsibilities and interfaces that should exist between the levels; and

(iv) The selection of the members to be allocated, which was explained through the analysis of factors such as routines, responsibility, availability, competencies, and hierarchies.

\subsection{Practical contributions}

This study has shown that the practical implementation of the help chain practice can contribute to the success of companies. The results demonstrate improvement in the company's operational performance through the employment of the help chain and troubleshooting. Among the operating results, we highlight the improvement in the OEE indicator, which was between $3.07 \%$ and $10.44 \%$ depending on the equipment, and the overall reduction in the department's overall scrap rates, which went from $8.6 \%$ to $8.10 \%$.

Another practical contribution was the fact that the company in question is planning and taking initiatives to expand and improve the help chain practice, with initial focus on:

(i) More complete evaluation of results;

(ii) The complete implementation of the projected structure by contemplating the first complete level of the help chain, along with the functioning of the QRPs and the triggering logic of the agents on this level;

(iii) The expansion of the first-level structure to other areas in addition to the corrective maintenance; and

(iv) The creation of specific help chains for each support area.

\subsection{Limitations and future studies}

The present study also had limitations as follows:

(i) The first level of the chain was not fully implemented on the decision of the senior management;

(ii) The triggering flow of the print area's help chain project is structured only in relation to 
the corrective maintenance area, with other sectors excluded;

(iii) The guidelines assume that the chosen scenario makes use of the OEE indicator and abnormalities reports;

(iv) The guidelines assume that there is no help chain structure already in place in the selected company, whether partially or completely;

(v) The guidelines assume that the prioritized support area has agents of all hierarchical levels available in all the shifts.

Therefore, the following opportunities have been identified for further research:

(i) The guidelines may be applied to other companies that have different processes and cultures as a way to validate them and evaluate their effectiveness in other scenarios, such when the OEE indicator is not being used or the abnormalities not being reported;

(ii) The guidelines could include a different approach toward defining the actors involved in the help chain if one or more of the agents involved in the support area are not available in all the shifts;

(iii) The method can be restructured by deleting or creating guidelines so that it can be applied in scenarios where a previously deployed help chain structure already exists and it is desirable to expand it to other support areas (as suggested to the printing company);

(iv) The interrelationships among the various chains that can be deployed to different support areas in the same scenario can be studied by analyzing them in relation with the structures and resources they compete for and/or share.

\section{References}

Andrade, A. (2001). Estudo de caso de implantação da cadeia de ajuda na empresa Alcoa. Sorocaba: Die Shop Help Chain.

Bendell, T. (2006). A review and comparison of six sigma and the lean organization. The TQM Magazine, 18(3), 255-262. http://dx.doi.org/10.1108/09544780610659989.

Campos, T. B., Maganhoto, S. L., Pacheco, A. R., \& Forcellini, F. A. (2010). Utilização da cadeia de ajuda no processo de desenvolvimento de produtos. In Anais do XXX Encontro Nacional de Engenharia de Produção. Rio de Janeiro: ABEPRO.
Carlile, P., \& Christensen, C. (2004). The cycles of theory building in management research. Boston: Harvard Business School. Working paper 05-057, version 5.0. Retrieved in 2015, January 7, from http://www.hbs.edu/ faculty/publication $\% 20$ files/05-057.pdf

Dresch, A. (2013). Design Science e Design Science Research como artefatos metodológicos para Engenharia de Produção (Dissertação de mestrado). Universidade do Vale do Rio dos Sinos, São Leopoldo.

Flinchbaugh, J. (2007, 19 april). Leading Lean: forging your help chain. Troy, MI: Assembly Magazine.

Horst, M. (2011). Método de diagnóstico para apoio à implantação da cadeia de ajuda em empresas de manufatura com processos de transformação automáticos (Dissertação de mestrado). Universidade Federal de Santa Catarina, Florianópolis.

Jusko, J. (2010). The end of the traditional Andon? Don't overlook new means of communication, like Twitter, on the plant floor. Cleveland: IndustryWeek.

Kamada, S. (2008). A cadeia de ajuda para manter a estabilidade produtiva. São Paulo: Lean Institute Brasil.

Lacerda, D. P., Dresch, A., Proença, A., \& Antunes, J. A. V., Jr. (2013). Design Science Research: método de pesquisa para a engenharia de produção. Gestão \& Produção, 20(4), 741-761. http://dx.doi.org/10.1590/ S0104-530X2013005000014.

Liker, J. K. (2005). O modelo Toyota: 14 princípios de gestão do maior fabricante do mundo. Porto Alegre: Bookman.

Liker, J. K., \& Meier, D. (2007). O modelo Toyota: manual de aplicação. Porto Alegre: Bookman.

Maganhoto, S. L. (2012). Fatores criticos de sucesso para a cadeia de ajuda: uma proposta para indústria metal mecânica (Dissertação de mestrado). Universidade Federal de Santa Catarina, Florianópolis.

Ohno, T. (1997). O Sistema Toyota de Produção: além da produção em larga escala. Porto Alegre: Bookman.

Oliveira, O. (2009). Manual de cadeia de ajuda. Joinville: Embraco.

Saurin, T. A., Ribeiro, J. L. D., \& Marodin, G. A. (2010). Identificação de oportunidades de pesquisa a partir de um levantamento da implantação da produção enxuta em empresas do Brasil e do exterior.Gestão \& Produção, 17(4), 829-841. http://dx.doi.org/10.1590/ S0104-530X2010000400015.

Shah, R., \& Ward, P. T. (2007). Defining and developing measures of lean production. Journal of Operations Management, 25(4), 785-805. http://dx.doi.org/10.1016/j. jom.2007.01.019.

Silva, I. B. D., Miyake, D. I., Batocchio, A., \& Agostinho, O. L. (2011). Integrando a promoção das metodologias Lean Manufacturing e Six Sigma na busca de produtividade e qualidade numa empresa fabricante de autopeças. 
Gestão \& Produção, 18(4), 687-704. http://dx.doi. org/10.1590/S0104-530X2011000400002.

Smalley, A. (2005). Creating basic stability. Boston: Lean Enterprise Institute.

Snee, R. D. (2010). Lean Six Sigma: getting better all the time. International Journal of Lean Six Sigma, 1(1), 9-29. http://dx.doi.org/10.1108/20401461011033130.

Sobek, D. K., II, \& Smalley, A. (2011). Understanding A3 thinking: a critical component of Toyota's PDCA management system. New York: CRC Press. http:// dx.doi.org/10.4324/9781439814055.

Spear, S., \& Bowen, H. K. (1999). Decoding the DNA of the Toyota production system. Harvard Business Review, 77, 96-108.

Wagner, A. C. (2011). Implantação da ferramenta da cadeia de ajuda em um projeto de gerenciamento da rotina numa empresa de compressores (Dissertação de mestrado). Universidade do Estado de Santa Catarina, Joinville. 
Annex A. Hierarchical structure of the Maintenance Area.

The hierarchical structure of the Maintenance area is subdivided into Maintenance Planning and Control (MPC), Mechanical, Electronics, Subassemblies and Warehouse, with the Maintenance and Warehouse Coordinator being responsible for the area management. The Electronics, Mechanical and Subassemblies divisions work together, and the Mechanical and Subassemblies divisions have employees who can work in both areas. This work involved only the employees from these three areas, since the PCM and Warehouse divisions have employees focused on specific scopes, not related to the help chain.

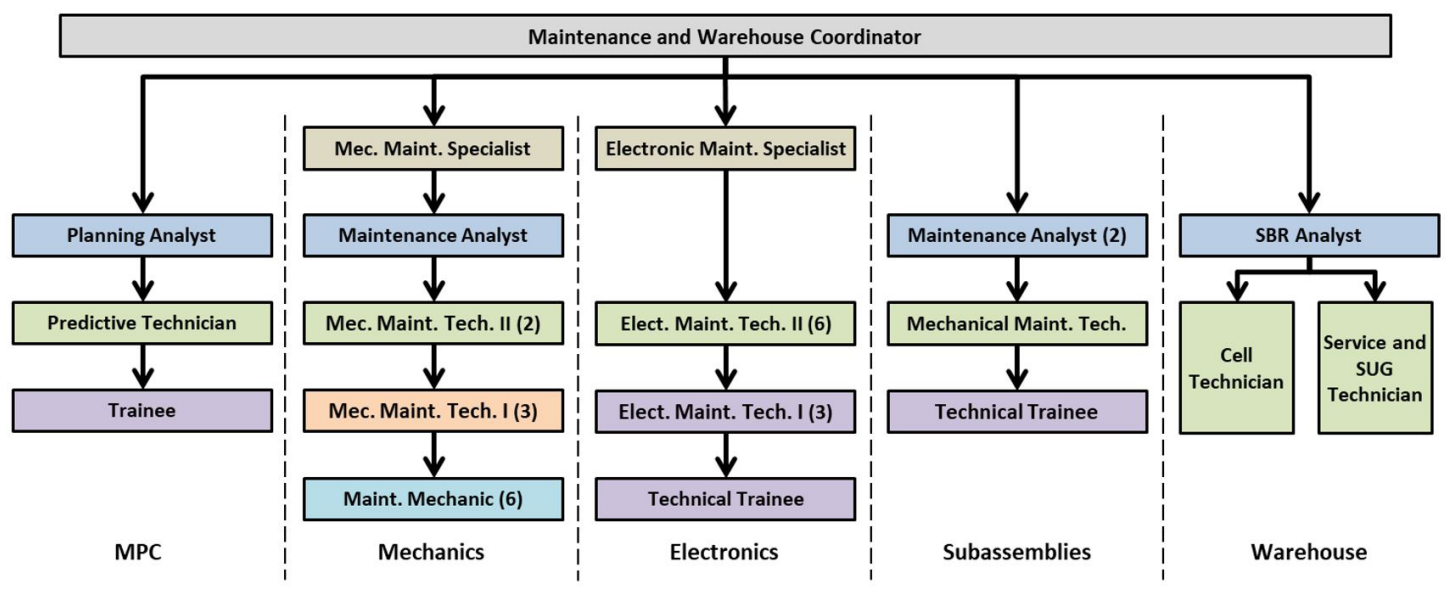

Annex B. Maintenance Area Positions (Electronic, Mechanical and Subassemblies) containing shift allocation and company time (date of admission).

\begin{tabular}{|c|c|c|}
\hline Role & Admission Date & Shift \\
\hline Maintenance Analyst & $03 / 10 / 2008$ & 1st shift \\
\hline Maintenance Analyst & $11 / 03 / 2008$ & 2nd shift \\
\hline Maintenance Analyst & 03/10/2008 & 3rd shift \\
\hline Maintenance Coordinator & $03 / 05 / 2007$ & Intermediate \\
\hline Electronic Maintenance Specialist & 09/11/2007 & Intermediate \\
\hline Mechanical Maintenance Specialist & $11 / 01 / 1979$ & Intermediate \\
\hline Technical Trainee & $07 / 14 / 2014$ & Intermediate \\
\hline Technical Trainee & $07 / 08 / 2013$ & Intermediate \\
\hline Maintenance Mechanic I & $04 / 14 / 2014$ & 1st shift \\
\hline Maintenance Mechanic I & $03 / 02 / 2009$ & 1st shift \\
\hline Maintenance Mechanic I & $01 / 15 / 2013$ & 2nd shift \\
\hline Maintenance Mechanic I & $09 / 07 / 2010$ & 2nd shift \\
\hline Maintenance Mechanic I & $01 / 03 / 2011$ & 3rd shift \\
\hline Maintenance Mechanic I & $04 / 02 / 2014$ & 3rd shift \\
\hline Electronic Maintenance Technician I & $10 / 10 / 2011$ & 1st shift \\
\hline Electronic Maintenance Technician I & $09 / 01 / 2010$ & 2nd shift \\
\hline Electronic Maintenance Technician I & $01 / 03 / 2011$ & 3rd shift \\
\hline Electronic Maintenance Technician II & 05/18/2009 & $1 \mathrm{st}$ shift \\
\hline Electronic Maintenance Technician II & $03 / 10 / 2008$ & 1st shift \\
\hline Electronic Maintenance Technician II & 03/09/2009 & 2nd shift \\
\hline Electronic Maintenance Technician II & $11 / 19 / 2007$ & 2nd shift \\
\hline Electronic Maintenance Technician II & $12 / 15 / 2008$ & 3rd shift \\
\hline Electronic Maintenance Technician II & 07/07/2008 & 3rd shift \\
\hline Mechanical Maintenance Technician I & $07 / 05 / 2010$ & 1st shift \\
\hline Mechanical Maintenance Technician I & $01 / 19 / 2009$ & 2nd shift \\
\hline Mechanical Maintenance Technician I & $03 / 02 / 2009$ & 3rd shift \\
\hline Mechanical Maintenance Technician II & $01 / 05 / 2007$ & 1 st shift \\
\hline Mechanical Maintenance Technician II & $09 / 11 / 2007$ & 2nd shift \\
\hline Mechanical Maintenance Technician II & $04 / 17 / 2000$ & 3rd shift \\
\hline
\end{tabular}


Annex C. Example of Maintenance Area Functional Competence Matrix (Electronic, Mechanical and Subassemblies).

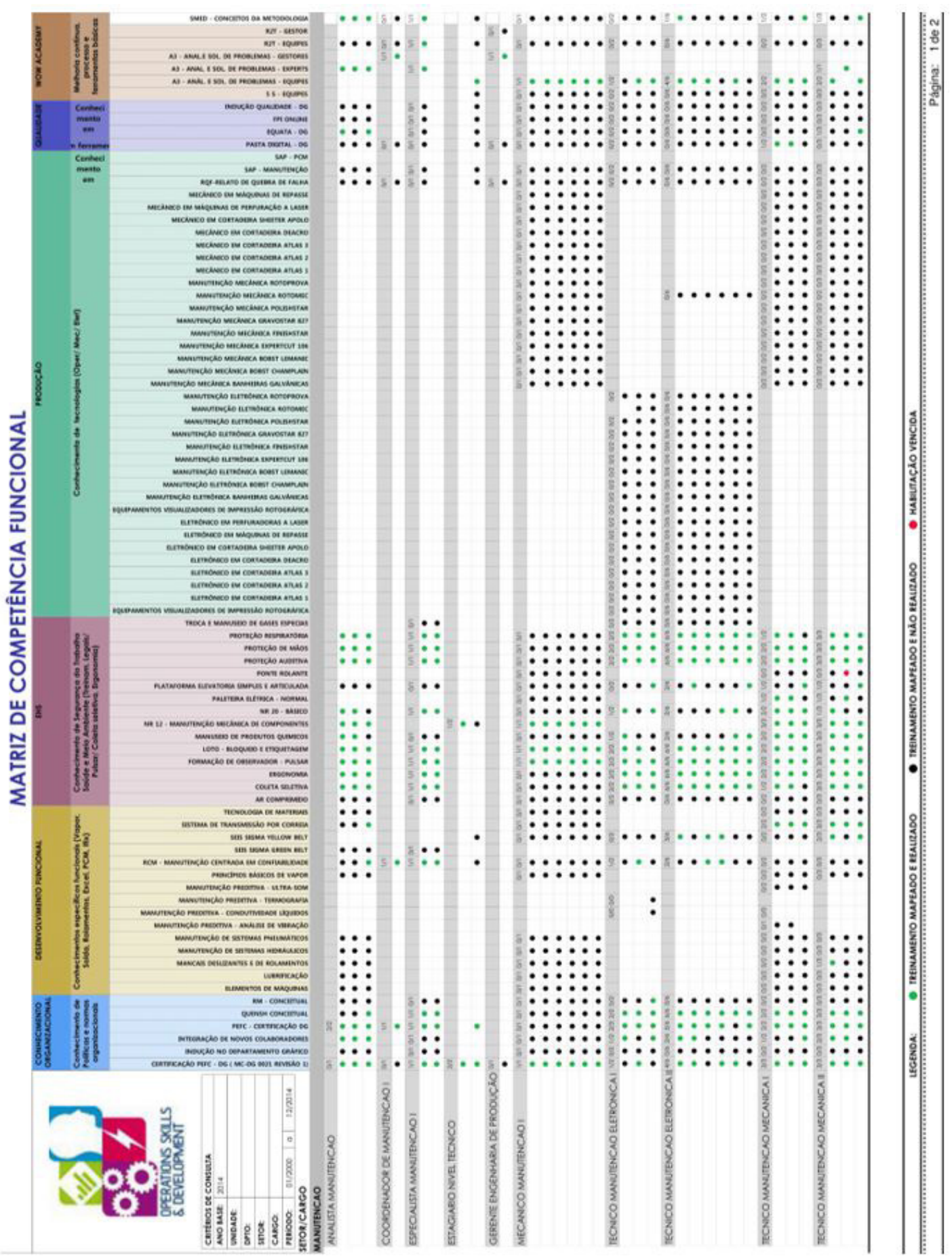

